\title{
Direito à mobilidade individual e a soberania dos Estados
}

Adriana Capuano de Oliveira

白 a partir de um caso extremamente elucidativo da problemática a ser levantada pelo livro que Rossana Rocha Reis expõe quão delicada e conflituosa é a questão que permeia o universo das migrações internacionais na contemporaneidade, especialmente daquelas correntes migratórias provenientes de países em desenvolvimento ou tidos como mais pobres em direção a países mais ricos ou industrializados. Políticas de imigração na França e nos Estados Unidos (19801998) é um livro altamente instigante e revelador de um mundo em plena mudança nesta época de globalização, e de reestruturação de um novo sistema internacional relacionado ao cenário do pós-guerra fria.

Chama-se Tampa o navio cargueiro - de bandeira norueguesa - que resgata 438 pessoas à deriva em um barco indonésio em alto-mar, nas proximidades da costa australiana. O que há de especial nesse resgate em alto-mar? $\mathrm{O}$ barco indonésio estava carregado de pessoas vindas do Afeganistão, em sua maioria, e alguns outros do Sri Lanka e do Paquistão. Estavam tentando chegar à Austrália. Depois do naufrágio e do resgate pelo Tampa, um polêmico impasse se estabelece: a Austrália se recusa a recebê-los alegando que a "carga" presente no navio pertence à Noruega (bandeira do navio) ou à Indonésia. A Indonésia, por sua vez, recusa-se a recebê-los num primeiro momento, colocando, aliás, o exército em seus portos para impedi-los da entrada no país. A imprensa se divide ao chamá-los de refugiados, por vezes, e de imigrantes ilegais, por outras. E os passageiros - a "carga" -, coroando a condição de absurdo que se instala, decidem pela recusa de retorno à Indonésia, quando essa aceita por fim recebê-los, e optam por uma greve de fome a fim de demonstrar a seriedade dessa recusa. Como bem descreve a autora ao descrever essa passagem histórica verdadeira (o acontecimento se dá no ano de 2001) como metáfora do que discutirá ao longo do livro: "Durante uma semana, o navio Tampa permaneceu no mar, vigiado pela marinha australiana, e impedido de atracar em qualquer lugar do mundo".

A questão que envolve a delicada polêmica reflete a condição de boa parte dos fluxos migratórios contemporâneos: centenas de milhares de pessoas desejosas de mudarem-se geograficamente em busca de um lugar onde suas condições de vida não estejam ameaçadas, ou onde possam conseguir melhores meios de sobrevivência, ou até mesmo o simples desejo da busca pela felicidade (na clássica versão norte-americana dos direitos e virtudes formadoras da nação... "the pursuit of hapiness"). O que as impede de realizar tal desejo ou, no caso de sua realização, as coloca sistematicamente dentro de situações de irregularidade? A dicotomia contemporânea entre o direito à liberdade de locomoção e sobrevivência digna do indivíduo e a questão da soberania dos Estados. É precisamente esse o debate colocado pelo livro que, por meio de dois exemplos magnânimos de 
países importantes receptores de fluxos migratórios e ao mesmo tempo berços característicos dos bastiões da liberdade, democracia e do respeito aos direitos individuais do Ocidente - Estados Unidos e França -, evidencia esse descompasso entre a soberania dos Estados e o direito dos indivíduos mediante a adoção das políticas migratórias mais recentes desses países.

Desde Westifália, a ordenação do sistema internacional dá-se pela condição da figura do Estado-nação, soberano nos limites de seu território, e que possui, além da clássica definição weberiana de monopólio legítimo do uso da violência, o monopólio legítimo também das condições de mobilidade entre os indivíduos, o que, para a dinâmica das migrações internacionais - que, por definição, atravessam fronteiras -, se coloca como uma questão de extrema importância a ser levantada, um verdadeiro paradoxo. Dessa forma, as políticas migratórias adotadas pelos governos, que favorecem por vezes uma maior abertura ou maiores restrições, se colocam como objeto de estudo central na compreensão da dinâmica desse processo.

De todo modo, é fato que, cada vez mais, com a crescente intersecção dos povos e as condições cada vez mais viáveis de transposição dos limites geográficos, em razão, sobretudo, das grandes inovações tecnológicas e do conseqüente barateamento do uso dessa tecnologia, os deslocamentos humanos têm ocorrido nesses últimos anos com uma profusão significativa. A alavanca de sustentação de tais deslocamentos figura, contudo, em um cenário anterior ao próprio, das disparidades e desigualdades profundas entre as regiões do globo. Embora a economia sinalize para um aspecto da realidade de globalização sem fronteiras, a cada novo momento de crise - ou mesmo de percepção de crise apenas -, compete aos governos nacionais, ainda, o modelo por excelência de ordenação do espaço internacional, a proteção de seus grandes símbolos de poder: seu povo, seu território e sua cultura. A cada novo dia surgem mais pessoas que vivem sob a jurisdição de um Estado do qual elas não possuem a nacionalidade; e a cada novo dia compete aos Estados legislar sobre pessoas que não são seus cidadãos. A questão colocada por Rossana é bastante clara e extremamente atual: "Quando o direito individual de um ser humano de fugir de um país no qual ele é perseguido [e acrescentaria, onde não enxerga possibilidades de sobreviver dignamente] se choca com o direito que o Estado possui de escolher quem pode entrar em seu território, como e quando, qual direito prevalece ou deveria prevalecer?".

Para questionamentos como esses não existem respostas fáceis ou prontas. As análises feitas ao longo do livro acerca das mudanças nas políticas migratórias dos dois países em questão - Estados Unidos e França -, particularmente nos últimos dezoito anos, vêm justamente trazer à tona elementos para uma reflexão sobre esses questionamentos. Ambos os países, juntos, abrigam praticamente um quarto da população imigrante do mundo, com uma larga vantagem para o caso norte-americano, que "hospeda" sozinho $20 \%$ da população imigrante mundial. Ambos os países possuem ampla tradição democrática e liberal, seja na vertente norte-americana das liberdades civis conquistadas ao longo do processo de formação da própria nação estadunidense, essa mesma formada por meio de imigrantes (sintetizada no ícone da 
Revolução Americana e na formação das treze colônias) seja na tradição republicana francesa, fundamentada no conceito de igualdade, liberdade e fraternidade, $\mathrm{e}$ adesão voluntária à nacionalidade francesa, pátria refúgio daqueles que eram perseguidos em nome da liberdade (sintetizada no ícone da Revolução Francesa). Ambos os países vivem hoje em dia a delicada polêmica de conciliação dessas duas magnitudes que, cada dia mais, parecem estar mais distantes.

Trabalhando de forma bastante séria e imparcial a reconstituição histórica das políticas recentes dos Estados Unidos e da França com relação às migrações e fronteiras, principalmente no que tange às políticas de reunificação familiar, refugiados, e no tocante aos imigrantes ilegais (ou indocumentados), Rossana vem questionar a vertente atual de alguns estudos relativos às migrações internacionais sobre a pretensa perda de soberania do Estado-nação e a noção de que uma "cidadania pós-nacional" estaria sendo constituída, graças justamente a essa pretensa perda de controle dos Estados sobre suas fronteiras e a conseqüente condição de "escolha" sobre aqueles que estariam sob seu poder e áreas de atuação política. Os fluxos cada vez mais abundantes de imigrantes que atravessam as fronteiras, mesmo que ilegalmente, estariam refletindo essa fraqueza do Estado-nação de capacidade de controle destas. Esse, por sua vez, ante o fortalecimento do regime internacional de direitos humanos, estaria sentindo-se tolhido e constrangido a ceder determinadas concessões com relação ao contingente populacional que não pertence à sua nação - seu povo -, mas que decide residir e viver em seu território, e que, em virtude de conquistas adquiridas pelo regime de direitos humanos, não pode prescindir de certas condições de sobrevivência e mesmo civilidade, como auxílio médico de urgência, educação, habitação. Tal cenário estaria evocando, por sua vez, uma dissociação entre a questão da nacionalidade e da cidadania.

De fato, ao pesquisarmos populações migrantes originárias de países em desenvolvimento, como no caso do Brasil, em direção a países desenvolvidos, encontraremos respostas que vêm corroborar esses argumentos, e não é raro ouvirmos um discurso veiculado pela boca do próprio imigrante de que esse se sente mais respeitado e mais "cidadão" em suas necessidades cotidianas (vestir, morar, alimentar-se, ter saúde e educação, e mesmo o respeito nas formas de tratamento interpessoais) do que no país de origem, de onde possui o status de cidadania legal. ${ }^{1}$ Entretanto, a essas percepções de "gozo" do usufruto de direitos mesmo sem o status legal de cidadão Rossana responde contundentemente afirmando a fragilidade de tais posições, pois a definição clássica de cidadania, desde a gênese do significado do conceito dentro da esfera da ciência política, centra-se no conceito de cidadania política, ou seja, ao nacional de um determinado país (relação povo e território) pertencem também os direitos políticos gradualmente conquistados ao longo da formação dos Estados modernos na tradição ocidental dos direitos, dentre os quais o mais simbólico reside na figura do direito ao voto e a ser votado. Nas palavras da autora:

De fato, a cidadania é, por definição, cidadania política. Qualquer tentativa de descrevê-la sem esse componente representa um empobrecimento do conceito. São os direitos políticos que definem quem está dentro e quem 
está fora, quem somos nós e quem são os outros $[\ldots]$ Na ausência de cidadania, ou melhor dizendo, na ausência da igualdade formal e do compartilhamento de direito políticos, os imigrantes serão sempre parte do outro e, portanto, estarão sempre sujeitos à perda de direitos e até mesmo à expulsão.

É precisamente esse mecanismo de vulnerabilidade dos imigrantes que Rossana explora ao analisar as políticas migratórias recentes dos dois países em questão. Tanto os Estados Unidos como a França vêm adotando medidas restritivas cada vez mais rigorosas com relação à entrada e permanência de estrangeiros em seu território, justificadas muitas vezes - especialmente depois dos ataques às Torres Gêmeas do 11 de Setembro - pelos argumentos relativos à segurança nacional deles. Inúmeras conseqüências podem ser exploradas a partir de tais condições, incluindo a polêmica discussão extremamente atual a respeito da criminalização das migrações internacionais, ou da visão do estrangeiro, do diferente, como um potencial criminoso ou terrorista. Essas políticas restricionistas evidenciam-se, sobretudo, na adoção de medidas que visam pouco a pouco à diminuição das categorias que já possuem ou possuíam alguns direitos de residência e/ou cidadania, bem como em medidas de expansão de condições provisórias em detrimento das definitivas (vistos de residência etc.), e nos critérios cada vez mais seletivos para a permissão da entrada legal em seus territórios - muito claramente percebidas nas políticas francesas dos últimos anos, em especial com a adoção das Leis Pasqua (1993) e da Lei Debré (1996); e nas políticas norte-americanas, em especial a referida no USA Patriotic Act (2001) e na adoção do Border Secu- rity and Visa Entry Reform Act (2002), ambas sancionada após os atentados às Torres Gêmeas. Figuras como Jean-Marie Le Pen e o partido do Front National de extrema-direita na França, ou manifestações favoráveis à proposição 187 na Califórnia, ou mesmo a extensão e fortificação do muro entre a fronteira Estados Unidos/México demonstram uma forte tendência de retrocesso na legitimidade que o regime de direitos humanos adquiriu ao longo dos anos subseqüentes à Segunda Guerra Mundial, comprovando assim a relevância e urgência na reflexão desses temas.

Diversos outros pontos compõem o corpo da obra, levando-nos à reflexão de importantes acontecimentos políticos, como a própria tensão e disputa de poder entre a esquerda e a direita na França, e o quanto a temática das migrações tem influenciado nas eleições recentes no país; a crise de identidade nos Estados Unidos, um país tradicionalmente formado por imigrantes mas cuja opinião pública recente não aceita mais a entrada de novos fluxos; a tentativa de unificação das políticas migratórias na Europa, de acordo com o conceito de União Européia; as convergências e divergências entre as situações vivenciadas pelos Estados Unidos e pela França no tocante às migrações. Referindo-se a este último ponto, é bastante interessante notarmos a diferença apontada pela autora de que os Estados Unidos possuem uma maior preocupação em reforçar o controle de suas fronteiras externas, em especial a fronteira dos Estados Unidos com o México, ou seja, quem pode entrar em território norte-americano; enquanto a França centra suas preocupações com o maior rigor no controle de suas fronteiras internas, de quem pode ou não ser cidadão 


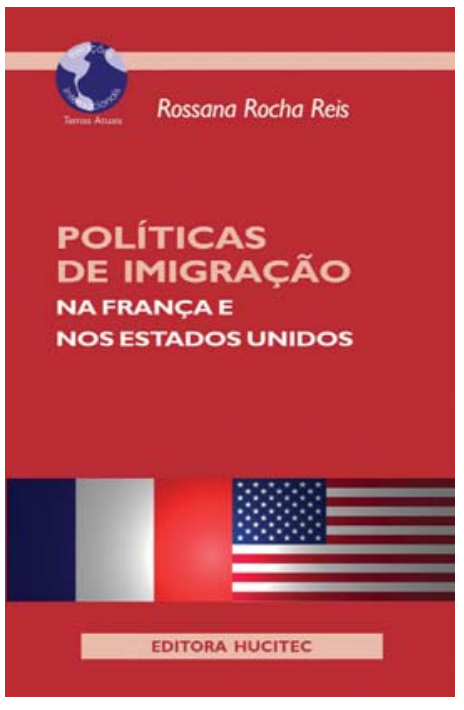

REIS, Rossana Rocha Politicas de imigração na França e nos Estados Unidos (19801998). São Paulo: Hucitec, 2007. 205p.

(Coleção Relações Internacionais n.7)

francês, graças aliás ao próprio contexto da União Européia, mais especificamente ao Acordo de Schengen, que coloca as fronteiras externas da França dimensionadas pela Europa como um todo.

Cabe uma última observação muito importante a respeito das análises feitas no livro. Quanto às políticas migratórias, não se chega de fato a um consenso, nem de um lado nem de outro (nem pela abertura nem pela restrição). Esse dado é de suma importância na argumentação da autora, que justifica a dificuldade por parte dos Estados no controle de seus fluxos migratórios e fronteiras não pela perda de parte de sua soberania ou por uma capacidade institucional desses, mas sim pela falta de consenso na adoção de políticas migratórias ao longo dos sucessivos governos e pela falta de vontade política que impera em boa parte deles.

Finalizando, a obra merece ainda um último adendo: como bem aponta Gildo
Marçal Brandão, que escreve o prefácio do livro, uma obra escrita por um autor brasileiro que se propõe a discutir e estudar política comparada entre dois países que não o nosso acarreta em ganho para os estudos da ciência política brasileira como um todo, ao internacionalizar nossa produção acadêmica para além das comparações entre nós e os outros - carro-chefe dos estudos de política comparada no Brasil. Assim como ele, faço votos que cada vez mais tenhamos "nossos próprios 'americanistas', 'europeístas', 'africanistas'" etc., e que este livro possa servir de exemplo para tanto.

Nota

1 Na afirmação de tais argumentos, baseiome, além de estudos bibliográficos, em uma própria pesquisa de campo realizada por mim com brasileiros residentes nos Estados Unidos entre os anos de $2001 \mathrm{e}$ 2002.

Adriana Capuano de Oliveira é professora do Departamento de Educação, Ciências Sociais e Política Internacional da Faculdade de História, Direito e Serviço Social da Unesp (campus de Franca). @-adcapuano@yahoo.com.br 